\title{
The effect of Willow extract, Bistep and their combination on some quality parameters of lettuce (Lactuca sativa $\mathbf{L}$.)
}

\author{
Arshad Yaseen ${ }^{1,2}$ - Mária Takácsné Hájos ${ }^{1}$ \\ ${ }^{1}$ University of Debrecen, Faculty of Agricultural and Food Sciences and Environmental Management, Institute of Horticultural Science, \\ H-4032 Debrecen, Böszörményi Street 138. \\ ${ }^{2}$ Salahaddin University-Erbil, College of Agricultural Engineering Sciences, Department of Horticulture, Kurdistan Region, Iraq \\ Kirkuk Road, 44002 \\ arshad.yaseen@agr.unideb.hu
}

\begin{abstract}
SUMMARY
The research described in this paper was conducted at the University of Debrecen, Farm and Regional Research Institute in its Botanical and Exhibition Garden, Hungary. The aim was to investigate the influence of plant biostimulants on the morphological parameters of three lettuce varieties (May King, Kobak and Great Lakes). Willow bark extract and Bistep were used through irrigation and spray onto the plant leaves with the amount of $5 \%$ Willow and 0,5\% Bistep. Vegetative parameters like head structure (1...10), head weight $\left(\mathrm{g} \mathrm{head}^{-1}\right)$, head closing (1 ...10), number of leaves, head diameter (cm), internal stem size (cm) and root weight ( $\left.\mathrm{g} \mathrm{head}^{-1}\right)$ were measured in 2019 and 2020. According to our results, vegetative parameters are significantly affected by plant varieties and treatments. In the experiment of 2019, important vegetative parameters were influenced by the Willow extract, while in the season of 2020 the most influenced parameters were under the impact of Bistep biostimulants followed by Willow+Bistep. However, the most favourable vegetative growth was recorded in the Kobak variety in the season of 2019 followed by May King and Great Lakes varieties in the season of 2020. On the other hand, the interaction effect of plant varieties and plant biostimulants on the vegetative parameters were varied from seasons. For example, for the season 2019, significantly the highest vegetative value was recorded for the interaction of May King variety treated with Willow extract, whereas in 2020, significantly the most influenced vegetative parameters were under the influence of the interaction of Bistep and May King variety followed by the interaction of Willow+Bistep and Kobak variety.
\end{abstract}

Keywords: plant biostimulants; lettuce varieties; vegetative quality; growing season

\section{INTRODUCTION}

Lettuce (Lactuca sativa L.) is the world's major cold-season cultivated indoor green leafy vegetable which is now grown in entire continents (Mou, 2009). Humanity has a long history with this crop for either domestication and cultivation. The plant was found in the Egyptian tomb paintings around 4,500 years ago (York and Garden, 1986). Nowadays, lettuce plays an important role in the human diet because it contains very low calory and high nutrient value. It can be eaten fresh (leaves) mainly in sandwiches and salads or cooked (internal stem) as it is common in China and Egypt. Nowadays, lettuce is described as the main sandwich ingredient. People who are eating the product as a diet need to maintain healthier and keep their nutrient balanced of their meals (Spence, 2020).

Due to the increasing demand by consumers, the global production of lettuce is growing constantly. In the last 10 years from 2008 to 2018, the world's total production of lettuce and chicory has improved by $14.3 \%$ from 23.8 million tonnes to 27.2 million tonnes respectively (Food and Agriculture Organization, 2020). China is the leading country for lettuce production which is accounted as the two-third total production area in Asia, followed by the United States. Hungary has also improved the total production by $13.6 \%$ from 7,523 tonnes in 2008 to 8,547 tonnes in 2018. In 2019, Hungary produced 8,358 tonnes of lettuce in 299 hectares; however, this amount was not filled the local market, so that 2,470 tonnes more were imported for local consumption (KSH, 2020).
Genetic, environment and their interactions are the main factors determining the nutrient content and quality parameters of lettuce (Mou, 2009). Consumers are always keen to find a better-looking product as (freshness, least damaged, morphologically nice experience, free from pesticides and chemicals). The morphological parameters (colour, texture, taste and texture) can determine the market price and successful marketing (Mampholo et al., 2016). Therefore, physical parameters are the first customer decision of buying a product (Artur, 2015). In recent years, different lettuce colours and shapes are mixed and packed for fresh-cut salads (Martínez-Sánchez et al., 2012).

Quality parameters can be improved by cultural methods especially through the management of nutrient solutions or the use of plant biostimulants (Rouphael et al., 2012). Nowadays, plant biostimulants are considered as innovated agronomic and environmentally friendly tool in plant production to secure crop performance improvement, help to reduce chemical nutrient supply, protect plants under biotic stress, improve nutrient uptake and improving the quality of horticulture crops (De Pascale et al., 2017; Rouphael and Colla, 2018; Bulgari et al., 2019). Many research papers have shown the positive influence of plant biostimulants on the improvement of leafy vegetable growth and quality as use of seaweed-based extract on spinach (Rouphael et al., 2018), applications of biostimulants (Activawe ${ }^{\circledR}$, Valagro S.p.A.) on the quality of rocket (Eruca sativa Mill.), spraying lettuce (Lactuca sativa L.) with $2.5 \mathrm{ml} \mathrm{L}^{-1}$ of biostimulants to improve tolerance to abiotic stresses (Lucini et al., 
2015), use biostimulants of Aminoplant with the amounts of $1.5 \mathrm{~L} \mathrm{ha}^{-1}$ and $3.0 \mathrm{~L} \mathrm{ha}^{-1}$ to improve the yield and nitrate reduction in spinach (Spinacia oleracea L.). So that, the aim of these experiments was to assess the role of genetic variability, plant stimulants (Willow bark extract and Bistep) in the improvement of vegetative quality of lettuce, also to evaluate the interaction of environmental factors (growing season) and interaction of genetic factors with plant biostimulants in vegetative parameters of lettuce (Lactuca sativa L.).

\section{MATERIALS AND METHODS}

\section{Experimental sight and plant materials}

The experiments were conducted at the University of Debrecen, Farm and Regional Research Institute in its Botanical and Exhibition Garden, Hungary during the season of Spring 2019 and 2020. Seeds of lettuce varieties (May King, Kobak and Great Lakes) were sown in 200-cell plastic trays on the $10^{\text {th }}$ February for each season then transplanted into a plastic tunnel on $18^{\text {th }}$ March.

\section{Experimental design and plant treatments}

The experiment was designed according to randomized complete block design (RCBD) with four different blocks (Control, Willow, Bistep and Willow+Bistep). The plant spacing was $25 \mathrm{~cm}$ between two plants and $30 \mathrm{~cm}$ between rows. Plants in each row were grown in two lines and each line contained 10 seedlings as repetition. The treatments were carried out every two weeks from transplanting till the harvest around 60-65 days after transplanting. The treatments were conducted as follows:

Control: plants treated with distilled water only (20 $\mathrm{ml}$ plant $^{-1}$ )

Willow: Plants irrigated with 5\% Willow bark extract with the amount of $60-70 \mathrm{ml} \mathrm{L}^{-1}$ every two weeks interval.

Bistep: plants sprayed with $0.5 \%$ Bistep by hand spray bottle with the amount of $20 \mathrm{ml}^{\text {plant }}{ }^{-1}$ every two weeks interval.

Willow+Bistep: Plants irrigated with 5\% Willow + sprayed with $0.5 \%$ Bistep at the same time with the same above time and amount.

Vegetative parameters like head structure (1...10), head weight $\left(\mathrm{g} \mathrm{head}^{-1}\right)$, head closing $(1 \ldots .10)$, number of leaves, head diameter $(\mathrm{cm})$, internal stem size $(\mathrm{cm})$ and root weight $\left(\mathrm{g} \mathrm{head}^{-1}\right)$ were measured in the two experimental years.

\section{Statistical analysis}

The obtained data was statistically analysed using the computer software SPSS version 25. The Analyses of variance $(5 \%$ level) were used to compare data of different treatments based on the significant difference at the probability level of $\left(\mathrm{p}_{=} 0.05\right)$ according to Tukey $\mathrm{HSD}^{\mathrm{a}, \mathrm{b}}$ Multiple Range Test. Some other data were analysed based on the comparison of means in the student t-test.

\section{RESULTS AND DISCUSSION}

\section{Effect of plant treatments on the vegetative parameters of lettuce}

Data shown in Table 1 represents all the vegetative parameters such as head structure (1..10), head weight $(\mathrm{g})$, head closing $(1 \ldots 10)$, number of leaves, head diameter $(\mathrm{cm})$, internal stem size $(\mathrm{cm})$ and root weight (g) which are significantly influenced by different foliar spray treatments compared with those of the control during 2019 and 2020. Comparing to the control plants, significantly the best head structure was recorded in the plants treated with Willow bark extract in 2019 and 2020. It was followed by Bistep in 2020 and Willow+Bistep in 2020. The highest head weight value was for the plant spraying with Willow in 2019 at $625.33 \mathrm{~g}$, whereas in 2020 the greatest head weight was for the plants treated with Bistep at $397.56 \mathrm{~g}$. Similar to the head weight, significantly the best head closing in 2019 was for the plants treated with Willow extract $(8.93 \mathrm{~g})$, while in 2020 was in the Bistep treatment. However, significantly the best head structure for both seasons was for the combination of Willow+Bistep for 2019 and 2020 respectively. Leaf number was the least influenced factor by the treatments, for example in the first season (2019), Willow extract significantly increased the number of leaves (54.40 leaves per head), whereas in the second season (2020) the combination of Willow+Bistep was the major influenced factor on the leaf number $(38.58$ leaves per head).

Significantly, the best head diameter was found in the plants treated with Bistep at $18.33 \mathrm{~cm}$ and $29.58 \mathrm{~cm}$ in both the spring season in 2019 and 2020, respectively. Internal steam size elongation is referring to the bolting and flowering in lettuce which representing the poor quality of the product. This parameter is mainly influenced by the soil and air temperature above $28^{\circ} \mathrm{C}$ (Nothmann, 1977). The data in Table 1 shows the varied influences of the treatments based on the seasons. In 2019, significantly the highest internal stem size was by Willow treatment $(6.50 \mathrm{~cm})$, while in 2020 the longest internal stem was in the plants treated with Willow+Bistep $(6.83 \mathrm{~cm})$. Roots are the most important part of plant development since the plant response differently to the water and fertilizer absorption in the soil (Jackson, 1995). In the season of 2019, the significantly higher root weight was detected by Willow treatment (38.13 g), while in 2020 the heaviest root weight was by plants sprayed with Bistep treatment $(35.14 \mathrm{~g})$. In general, comparing to the control, the better vegetative quality parameter for the season 2019 was found in the plants irrigated with Willow bark extract, whereas the best vegetative quality parameter in 2020 was found in the plants treated with Willow+Bistep. 


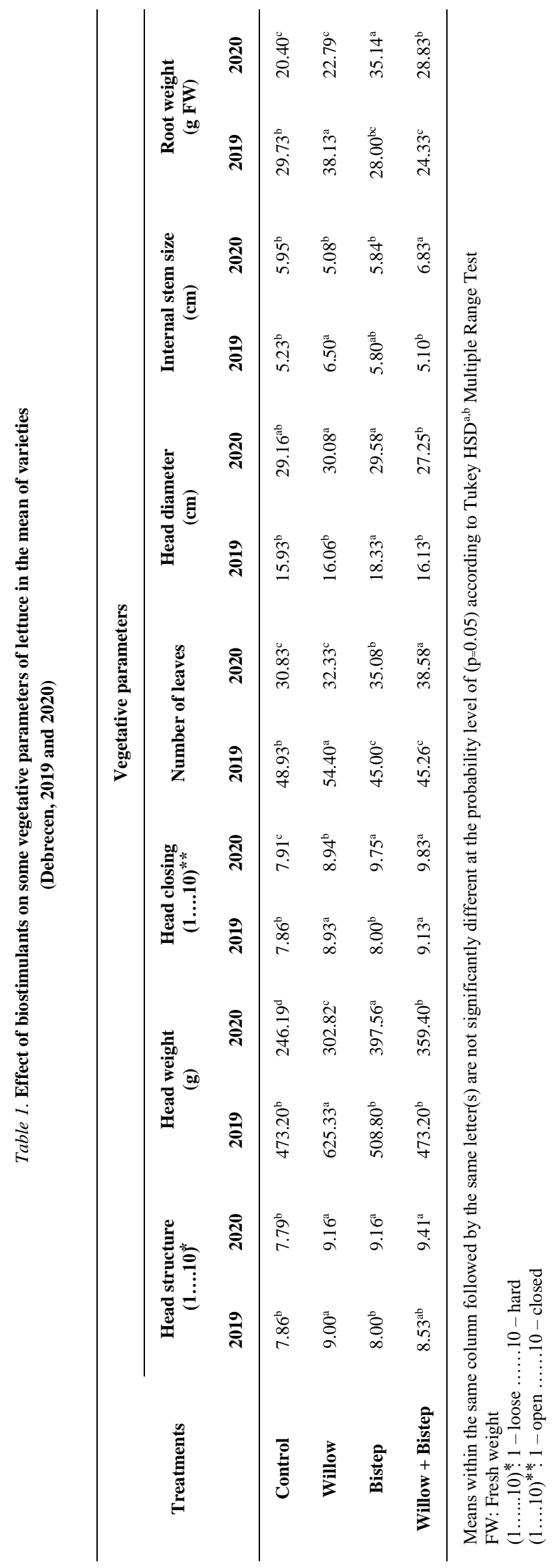




\section{Effect of lettuce variety on the vegetative parameters of lettuce}

Genotypically, plants in the same species are different for their vegetative parameters, this can be clearly noticed in Table 2 . Plant phenotypes can also be changed based on the genetic make-up and environmental factors and their interactions (Mou, 2009; Fasahat et al., 2015). There is a significant genotypic variation within lettuce species - crisphead, leaf, romaine, butterhead, and wild lettuces (Mou, 2005). Our results show that except for the Great Lakes variety in the season of 2019, plants were not significantly different for their head structure, however, head weight was significantly different among the varieties. In both seasons, Great Lakes produced the greatest head weight comparing to the Kobak and May King at $680.75 \mathrm{~g} \mathrm{head}^{-1}$ and $404.70 \mathrm{~g} \mathrm{head}^{-1}$ for Spring 2019 and 2020 respectively. Head closing is another important and considered phenotype factor in quality evaluation that shows the head formation appearance of the lettuce head. In 2019 nonsignificant head closing was found between May King and Kobak variety, while Great Lakes recorded significantly the poorest head closing among them (6.50 on the scale of 10$)$, wherein 2020 the poorest head closing was found in the May King variety ( 8.45 on the scale of 10$)$. Leaf number in lettuce is another most important vegetative parameter because the main eaten part is fresh leaves. Table 2 shows a significant difference among the varieties. Naturally, May King and Kobak varieties produce a higher number of leaves than Great Lakes. This has been proven in our results. In both seasons significantly greater leaves were measured in both May King and Kobak comparing to the Great Lakes variety. Head diameter, on the other hand, is the horizontal improvement of the head which gives a better appearance and greater head formation. In 2019, the largest head diameter was shown in the Great Lakes variety $(18.95 \mathrm{~cm})$, while in 2020 it was for the May King and Great Lakes varieties $(30.75$ and $29.56 \mathrm{~cm}$, respectively). Rapid improvement of internal stem size due to environmental or genetic variation is severely influences the quality and marketability of the plant (Rader and Karlsson, 2006; Fukuda et al., 2012). The nature changes of the internal stem size are based on the plant species (Zhao and Carey, 2009). As can be seen in Table 2, the significantly largest internal stem size is in the Kobak variety in both seasons $(6.12 \mathrm{~cm}$ and $8.28 \mathrm{~cm}$ ) in 2019 and 2020. Plants in the same variety having bigger root growth which means it can absorb nutrients more and water from the soil and can grow better than others. Comparing to other vegetables like carrots and some brassicas, lettuce produces a shallow root system (Greenwood et al., 1984; Jackson and Stivers, 1993; Thorup-Kristensen and Sørensen, 1999). Based on the data in Table 2, significantly the greatest root fresh weight in 2019 was found by the Great Lakes variety (36.65 g FW), while in 2020, the May King variety had a significantly superior rooting system (33.28 g FW).

\section{Interaction effect of plant variety and plant biostimulants on the vegetative parameters of lettuce}

Environmental and genetic factors are the main two factors that can significantly influence plant growth and development of the same variety. The environmental factors are the following - light, temperature, $\mathrm{CO}_{2}$, humidity, and nutrition (Gruda, 2005). In this regard, the use of plant biostimulants, which is supplying extra nutrients to the plants, can play an enormous role in the nature growth of the plants. Head structure is an important quality parameter that can attract customer buying the product and shows the plant healthiness. Table 3 illustrates some positive impacts of the interaction of plant variety and treatments. In the experiment of 2019, significantly the best head structure was measured for the May King variety treated with Willow and Kobak variety treated with Bistep (10.00 and 10.00 on a scale of 10) followed by May King variety treated with Willow+Bistep and Kobak in control (9.40 and 9.20 on a scale of 10). In 2020 except for the May King in control, there was no significant difference between the interaction of the treatments and the varieties.

Commercially, head weight is the major concerned quality parameter since it shows the final yield of the product (Fonseca, 2006). According to our results, significantly the best head weight was found in 2019 for the interaction of Willow treatment and Great Lakes variety $\left(807.20 \mathrm{~g} \mathrm{head}^{-1}\right)$, followed by Willow+Bistep treatment and Great Lakes variety $\left(737.40 \mathrm{~g} \mathrm{head}^{-1}\right)$. Similar results were recorded in 2020, significantly the greatest head weight was detected for the interaction of Willow treatment and Great Lakes variety (530.05 $\left.\mathrm{g} \mathrm{head}^{-1}\right)$. Head closing is the enclosure of its leaves in a head structure which was also varied among the interaction of plant variety and treatments. In 2019, significantly the best head closing was for the interaction of Willow treatment and May King variety (10.00 on a scale of 10). The same value was detected by Bistep and Kobak combination (10.00 on a scale of 10), whereas in 2020 significantly the best head closing was for the interaction of Bistep and May King and Great Lakes varieties. Leaf number, on the other hand, was the least influenced parameter by the interaction of plant variety and treatments. Significantly, the highest leaf number in the 2019 experiment was measured for the Kobak variety treated with Willow extract (66.00 leaves per head), while in 2020 significantly the highest leaf number was for the same variety (Kobak) treated with Willow+Bistep $(63.00$ leaves per head). Head diameter is the horizontal expansion of the head which provides the improvement of the head morphology and shape formation of the product. The head diameter was varied based on the growing season. In 2019, significantly, the best head diameter was recorded for the interaction of Great Lakes variety sprayed with $0.5 \%$ Bistep $(21.80 \mathrm{~cm})$, while in 2020 significantly the best head diameter was for the same variety treated with Willow bark extract $(34.50 \mathrm{~cm})$. The rapid improvement of the internal stem size in lettuce forces the plant to produce flowers and finishes the vegetative growth period to maturity and seed production. 


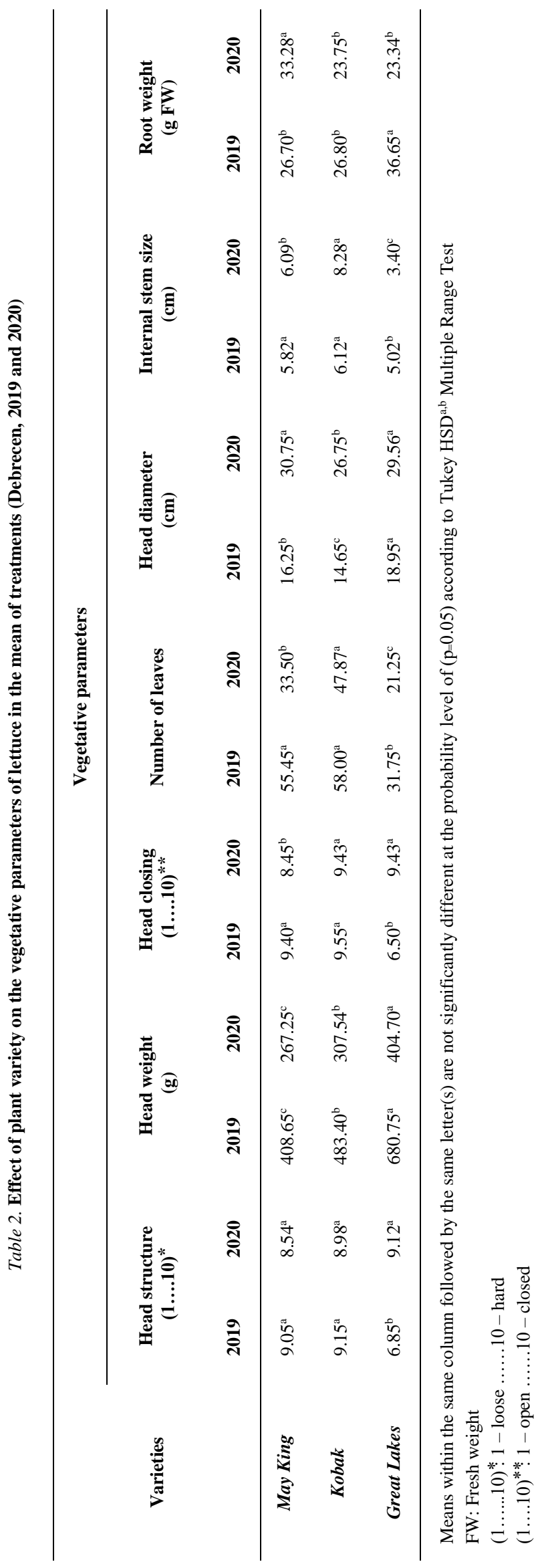




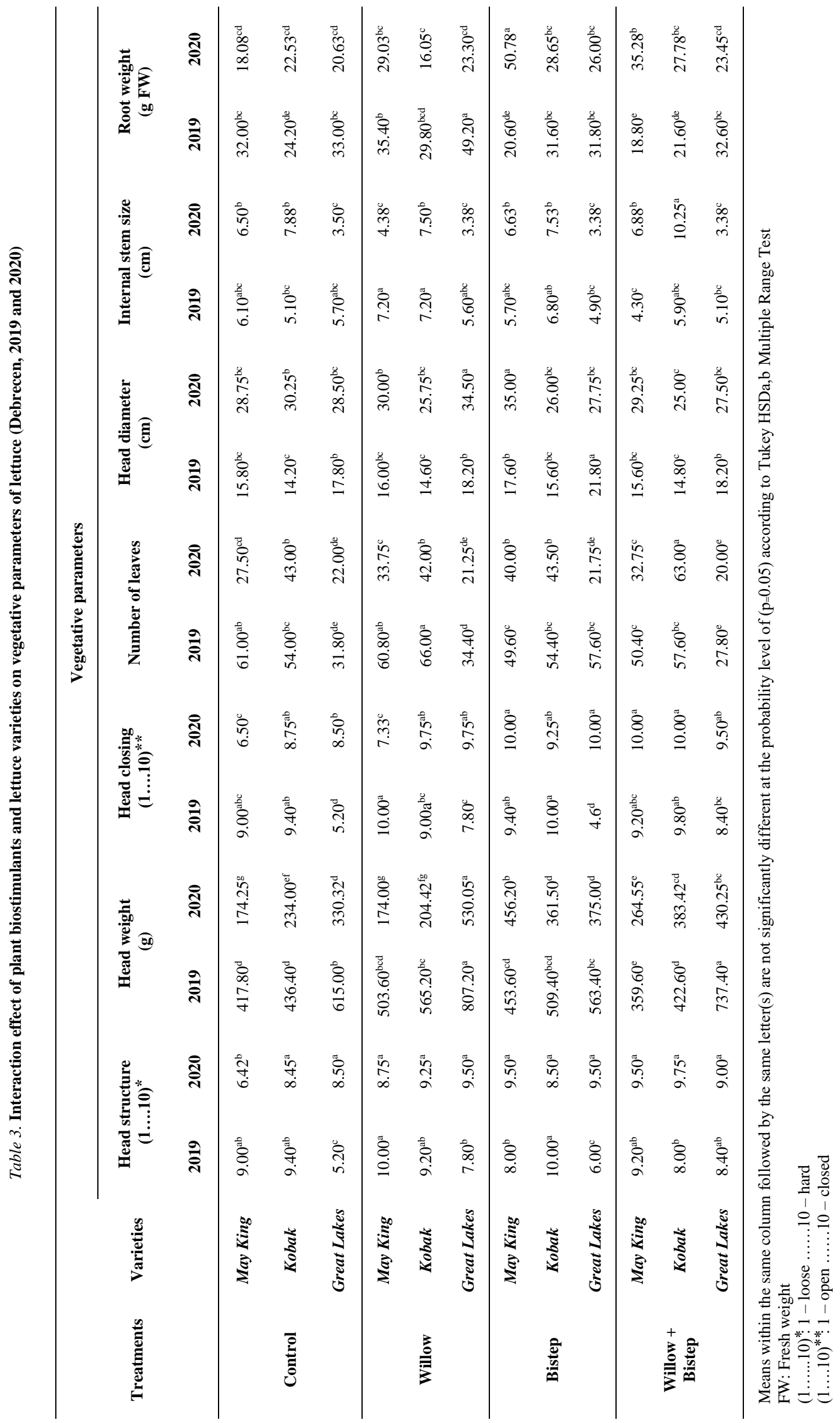


As it is shown in Table 3, in 2019 the May King and Great Lakes varieties treated with Willow extract have significantly improved the internal stem size (7.20 and $7.20 \mathrm{~cm}$, respectively), while in 2020 significantly the highest internal stem size was for the Kobak variety treated with Willow and Bistep $(10.25 \mathrm{~cm})$. Lettuce naturally produces a very shallow root system. In our experiment data, in 2019 the best root system was by the Great Lakes treated with Willow extract $(49.20 \mathrm{~g}$ FW), whereas in 2020 the best root formation was by the May King treated with Bistep (50.78 g FW).

The reason for the major differences between the growing seasons might be due to the environmental factors primarily maximum and minimum temperature during the growing period. Geissler (1985) has mentioned that the water core in the lettuce occurs when the air temperature is lower than the soil temperature. So many research papers have demonstrated the influence of low and high temperature on vegetable fruits. For example flower and fruit malformations induced by low temperature in tomatoes and bell peppers (Aloni et al., 1999; Adams et al., 2001), grittiness in greenhouse cauliflower production is related to low temperature and water deficiency (Geissler, 1985), the well-known colour changes of vegetable fruits due to the influence of temperature (Geissler, 1985; Zipelevish et al., 2000; Domis et al., 2002). High temperatures above the optimum that the plant requires has also negative influence on the crop quality especially for the greenhouse vegetable production when there is no sufficient ventilation (Gruda, 2005). Leaf burning due to the stomata opening and increasing water evaporation is the first reaction of the low ventilation and rising greenhouse air temperature (Bakker, 1984).

So that, Figures 1 and 2 show the two seasons of minimum and maximum temperature fluctuations. These data might be the main reason for the quality differences between the two growing seasons. In general, the average temperature in 2019 is much higher than in 2020 which could negatively influence some of the parameters as internal stem size.

Figure 1. Minimum temperature during the lettuce growing period of 2019 and 2020

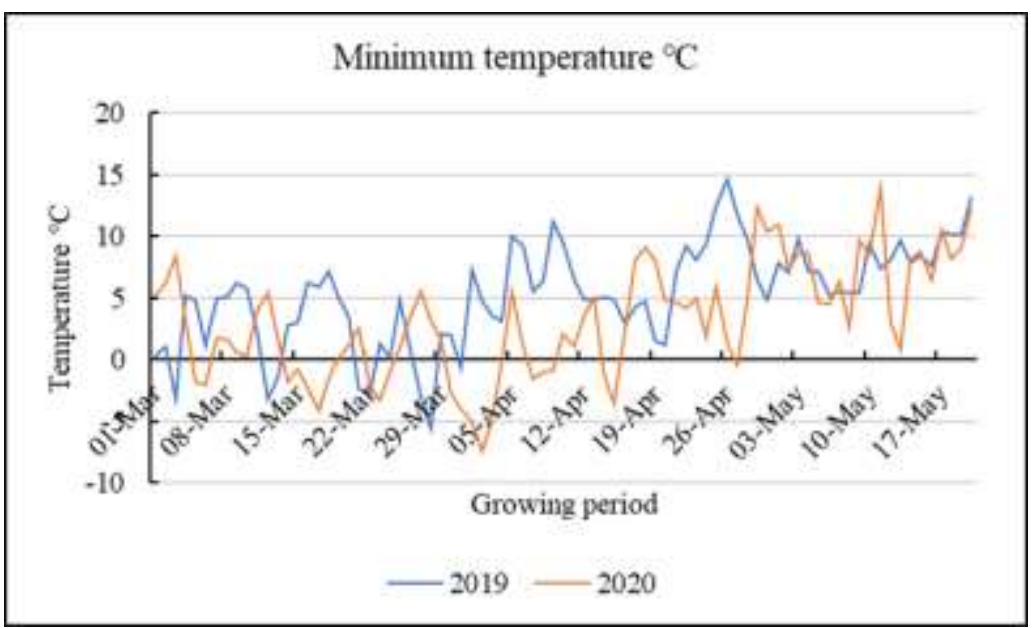

Figure 2. Maximum temperature during the lettuce growing period of 2019 and 2020

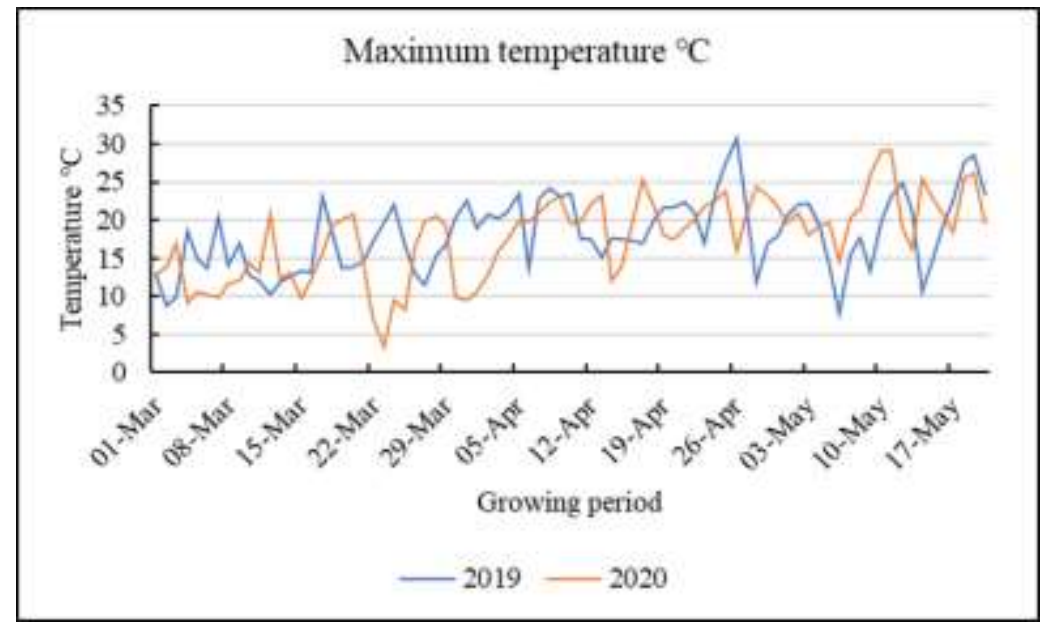




\section{CONCLUSIONS}

Our results confirm that plant biostimulants can play an important role in improving the vegetative parameters of lettuce. However, to evaluate the best treatment, all the vegetative parameters have to be taken into account. Willow could improve most of the physical quality parameters, while the improvement of internal stem size is accounted as a negative quality character in plant variety. However, varieties were varied based on their natural growth of vegetative parameters. We can conclude that considering the environmental and genetic factors, the best vegetative parameters in 2019 was for the interaction of Great Lakes variety treated with Willow+Bistep while in 2020 the best vegetative quality property was found in the Great Lakes variety treated with Willow bark extract.

\section{REFERENCES}

Adams, S.R.-Cockshull, K.E.-Cave, C.R.J. (2001): Effect of temperature on the growth and development of tomato fruits. Annals of Botany, 88 (5), pp. 869-877. [Online]. Available at: doi:10.1006/anbo.2001.1524.

Aloni, B.-Pressman, E.-Karni, L. (1999): The effect of fruit load, defoliation and night temperature on the morphology of pepper flowers and on fruit shape. Annals of Botany, 83 (5), pp. 529 534. [Online]. Available at: doi:10.1006/anbo.1999.0852

Artur, K. (2015): Factors influencing the decisions to buy and consume functional food. British Food Journal, 117 (6), Emerald Group Publishing Limited., pp. 1622-1636. [Online]. Available at: doi:10.1108/BFJ-08-2014-0301.

Bakker, J.C. (1984): Effect of changes in ventilation on cucumber Acta Hort., 148, pp.519-524.

Bulgari, R.-Franzoni, G.-Ferrante, A. (2019): Biostimulants application in horticultural crops under abiotic stress conditions. Agronomy, 9 (6), p.306. [Online]. Available at: doi:10.3390/agronomy9060306.

Domis, M.-Papadopoulos, A.P.-Gosselin, A. (2002): Greenhouse tomato fruit quality. Horticult. Rev, 26, pp. 239-349.

Fasahat, P., Rajabi, A., Mahmoudi, S. B., Noghabi, M. A., \& Rad, J. M. (2015): An Overview on the Use of Stability Parameters in Plant Breeding. Biometrics \& Biostatistics International Journal, 2 (5), pp. 149-159. [Online]. Available at: doi:10.15406/bbij.2015.02.00043.

Fonseca, J.M. (2006): Postharvest quality and microbial population of head lettuce as affected by moisture at harvest. Journal of Food Science, 71 (2), pp.M45-M49. [Online]. Available at: doi:10.1111/j.1365-2621.2006.tb08906.x.

Food and Agriculture Organization (2020): FAOstat statistical database. [Online]. Available at: http://www.fao.org/faostat/en/\#data/QC [Accessed 18 November 2020].

Fukuda, M.-Matsuo, S.-Kikuchi, K.-Mitsuhashi, W.-Toyomasu, T.-Honda, I., (2012): Gibberellin metabolism during stem elongation stimulated by high temperature in lettuce. Acta Horticulturae, 932, pp. 359-364. [Online]. Available at: doi:10.17660/actahortic.2012.932.52.

Geissler, T. (1985): Gem"useproduktion unter Glas und Plasten. Berlin: VEB Deutscher Landwirtschaftsverlag.

Greenwood, D.J.-Gerwitz, A.-Stone, D.A.-Barnes, A., (1984). Root development of vegetable crops. Plant and soil, 68 (1), pp. 75 96.

Gruda, N. (2005): Impact of environmental factors on product quality of greenhouse vegetables for fresh consumption. Critical Reviews in Plant Sciences, 24 (3), pp. 227-247. [Online]. Available at: doi:10.1080/07352680591008628.

Jackson, L.E. (1995): Root architecture in cultivated and wild lettuce (Lactuca spp.). Plant, Cell \& Environment, 18 (8), pp. 885-894.
[Online]. Available at: doi:10.1111/j.13653040.1995.tb00597.x.

Jackson, L.E.-Stivers, L.J. (1993): Root distribution of lettuce under commercial production: Implications for crop uptake of nitrogen. Biological Agriculture and Horticulture, 9 (3), pp. 273-293. [Online]. Available at: doi:10.1080/01448765.1993.9754639.

KSH (2020): Production and use of main vegetables (2014-)(13/18). [Online]. Available at: https://www.ksh.hu/stadat_annual_4_1 [Accessed 18 November 2020].

Lucini, L.-Rouphael, Y.-Cardarelli, M.-Canaguier, R.-Kumar, P.Colla, G. (2015): The effect of a plant-derived biostimulant on metabolic profiling and crop performance of lettuce grown under saline conditions. Scientia Horticulturae, 182, Elsevier B.V., pp. 124-133. [Online]. Available at: doi:10.1016/j.scienta.2014.11.022.

Mampholo, B.M.-Maboko, M.M.-Soundy, P.-Sivakumar, D. (2016): Phytochemicals and Overall Quality of Leafy Lettuce (Lactuca sativa L.) Varieties Grown in Closed Hydroponic System. Journal of Food Quality, 39 (6), pp. 805-815. [Online]. Available at: doi:10.1111/jfq.12234.

Martínez-Sánchez, A.-Luna, M.C.-Selma, M.V.-Tudela, J.A.Abad, J.-Gil, M.I. (2012): Baby-leaf and multi-leaf of green and red lettuces are suitable raw materials for the fresh-cut industry. Postharvest Biology and Technology, 63 (1), pp. 1-10. [Online]. Available at: doi:10.1016/j.postharvbio.2011.07.010.

Mou, B. (2005): Genetic variation of beta-carotene and lutein contents in lettuce. J Amer Soc Hort Sci, 130 (6), pp .870-876.

Mou, B. (2009): Nutrient Content of Lettuce and its Improvement. Current Nutrition \& Food Science, 5 (4), pp. 242-248. [Online]. Available at: doi:10.2174/157340109790218030.

Nothmann, J. (1977): Effects of soil temperature on head development of Cos lettuce. Scientia Horticulturae, 7 (2), pp. $97-$ 105. [Online]. Available at: doi:10.1016/0304-4238(77)900486.

De Pascale, S.-Rouphael, Y.-Colla, G. (2017): Plant biostimulants: Innovative tool for enhancing plant nutrition in organic farming. European Journal of Horticultural Science, 82 (6), pp. 277-285. [Online]. Available at: doi:10.17660/eJHS.2017/82.6.2.

Rader, H.B.-Karlsson, M.G. (2006): Northern field production of leaf and romaine lettuce using a high tunnel. HortTechnology, 16 (4), pp. 649-654. [Online]. Available at: doi:10.21273/horttech.16.4.0649.

Rouphael, Y.-Cardarelli, M.-Bassal, A.--Leonardi, C.-Giuffrida, F.Colla, G. (2012): Vegetable quality as affected by genetic, agronomic and environmental factors. Journal of Food, Agriculture \& Environment, 10 (3\&4), pp. 680-688.

Rouphael, Y.-Giordano, M.-Cardarelli, M.-Cozzolino, E.-Mori, M.-Kyriacou, M.C.-Bonini, P.-Colla, G. (2018): Plant-and seaweed-based extracts increase yield but differentially 
modulate nutritional quality of greenhouse spinach through biostimulant action. Agronomy, 8 (7), pp. 1-15. [Online]. Available at: doi:10.3390/agronomy8070126.

Rouphael, Y.-Colla, G. (2018): Synergistic biostimulatory action: Designing the next generation of plant biostimulants for sustainable agriculture. Frontiers in Plant Science, 9, p.1655. [Online]. Available at: doi:10.3389/fpls.2018.01655.

Spence, C. (2020): Gastrophysics: Nudging consumers toward eating more leafy (salad) greens. Food Quality and Preference, 80, Elsevier., p. 103800. [Online]. Available at: doi:10.1016/j.foodqual.2019.103800.

Thorup-Kristensen, K.-Sørensen, J.N. (1999): Soil Nitrogen Depletion by Vegetable Crops with Variable Root Growth. Acta Agriculturae Scandinavica Section B: Soil and Plant Science, 49 (2), pp. 92-97. [Online]. Available at: doi:10.1080/09064719950135597.
York, N.-Garden, B. (1986): Lettuce and the sycomore: sex and romance in ancient Egypt. Economic botany, 40 (1), pp. 4-15.

Zhao, X.-Carey, E. (2009): Summer production of lettuce, and microclimate in high tunnel and open field plots in kansas. HortTechnology, 19 (1), pp. 113-119. [Online]. Available at: doi:10.21273/hortsci.19.1.113.

Zipelevish, E.-Grinberge, A.-Amar, S.-Gilbo, Y.-Kafkafi, U. (2000): Eggplant dry matter composition fruit yield and quality as affected by phosphate and total salinity caused by potassium fertilizers in the irrigation solution. Journal of Plant Nutrition, 23
(4), pp
431-442.
[Online].
Available at: doi:10.1080/01904160009382030. 
